\title{
Autoregressive Models of the Random fields-A Survey
}

\author{
Hussein A. Abdulkadhim ${ }^{1}$, Mayyadah S. Ibrahim², Ali N. Albu-Rghaif ${ }^{3}$ \\ ${ }^{I}$ Dept. of Communication Eng., College of Engineering, University of Diyala, Diyala, Iraq. \\ ${ }^{2}$ Dept. of Power Eng., College of Engineering, University of Diyala, Diyala, Iraq. \\ ${ }^{3}$ Dept. of Computer Eng., College of Engineering, University of Diyala, Diyala, Iraq. \\ hussein73@mail.ru,Eng.mayyadah@yahoo.com,ali.alburghaif@yahoo.com
}

\begin{abstract}
Autoregressive (AR) random fields are widely use to describe changes in the status of real-physical objects and implemented for analyzing linear \& non-linear models. AR models are Markov processes with a higher order dependence for one-dimensional time series. Actually, various estimation methods were used in order to evaluate the autoregression parameters. Although in many applications background knowledge can often shed light on the search for a suitable model, but other applications lack this knowledge and often require the type of trial errors to choose a model. This article presents a brief survey of the literatures related to the linear and non-linear autoregression models, including several extensions of the main mode models and the models developed. The use of autoregression to describe such system requires that they be of sufficiently high orders which leads to increase the computational costs
\end{abstract}

Index Terms- Autoregressive process, Exponential autoregressive models, Threshold autoregressive models, Vector autoregressive models.

\section{INTRODUCTION}

Over the last years, the interesting on linear and nonlinear models has been growing steadily. Most of the processes occurring in reality are largely nonlinear [1]. Therefore, in many practical applications, nonlinear models are required to achieve acceptable forecast accuracy and to ensure sufficiently close forecasts [2]. Generally, the structures of dynamic phenomena can be characterized by time-series models [3,4]. In practice, one often has to deal with processes, the realization of which is more complex and at the same time allows efficient solution of problems of analysis, synthesis and simulation. Successful in this respect are AR models, in which recursive functions are used [5-7]. Various nonlinear models, namely: Bilinear models, threshold AR models, exponential AR models, statedependent models, spatial temporal conditional autoregressive and double stochastic models [8,9]. Also, several kinds of analysis of autoregressive models, such as onedimensional and multivariate AR models, an AR model with exogenous variables, a locally stationary autoregressive model, and an autoregressive model of a radial base [10,11]. Nonlinear models not only provide a better fit to data, but can also identify rich dynamic characteristics such as volatility, chaos, the behavior of the limit cycle and cyclic oscillations, which are not taken into account by linear models [12]

A function whose value for each value of the independent variable is a random variable called a random function [10,11]. If it is an independent quantity, such functions called random (or stochastic) processes. The random process is an undefined function, and the ensemble of functions $x(t) \quad x(t) \quad x(t)$, each of which can appear during a separate 
experiment. Each of the ensemble functions is called the realization of a random process [13]. From a physical point of view, such a process represents oscillations with respect to a certain constant value. It is supposed, first of all, to receive information about the development of the process at the moment, to predict the process indicators during a short period, taking into account the continuity of the data and the degree of their influence on the process [14].

\section{AUTOREGRESSIVE MODELS WITH MULTIPLE ROOTS OF THE CHARACTERISTIC EQUATION}

In signal processing and statistics fields, the autoregressive model defines as an illustration of the type of random process. This is because of description of signals and interference with the help of spatial-temporal random processes makes it possible to approximate mathematical models to real jamming situations in the most diverse information systems used in medicine, earth monitoring, navigation, etc. The output variable indicated by AR model is dependent on its own prior values linearly and on the stochastic term (the incompletly predicted term). However, the model has the form of a stochastic difference formula $[5,7,10]$.

The processes of autoregression of order $\mathrm{m}$ can be given by the following stochastic difference equation $[5,6,9]$ :

$$
x_{i}-\beta \xi_{i}=\rho_{1} x_{i-1}+\rho_{2} x_{i-2}+\ldots+\rho_{m} x_{i-m}, i=2,3, \ldots, n,
$$

where $\xi_{i}, i=1,2, \ldots, n$, Gaussian independent random variables with zero mean \& unit variance, and the coefficient determines the scale of the random field of $x_{i}$. In the analysis of the sequence (1), the Yule-Walker (YW) equations [7,8] is used. YW is a wide-ranging method to estimate parameters of an autoregressive process. YW is also known to give preconceived results and the formula for asymptotic value of the displacement is known [8, 10, 11]. The coefficients can be found on the basis of the experimental material with the help of the Yule-Walker equations [5, 7, 8] or obtained on the basis of the known properties of dynamical systems. The correlation function of the sequence (1) at different roots $R_{c}, c=$ $1,2, \ldots, m$, of characteristic equation is:

$$
R^{m}-\rho_{1} R^{m-1}-\rho_{2} R^{m-2}-\ldots-\rho_{m}=0
$$

and the condition of stability $\left|R_{c}\right|<1, c=1,2, \ldots, m$, is sum of the exponents. In the general case, when the coefficients of Eq. (1) are large, and study of the properties of correlation function is a rather complicated problem. The characteristic equation (2) with a root $R=\rho$ multiplicity has the form $(R-\rho)^{m}=0$ and $\mathrm{AR}(m=1)$ is written in the operator form as follows $[12,15]$ :

$$
x_{i}=\frac{\beta \xi_{i}}{\left(1-\rho R^{-1}\right)^{m}},
$$

where $R^{-k} x_{i}=x_{i-k}$. To determine the coefficients $\left(\rho_{1}, \rho_{2}, \ldots, \rho_{m}\right)$ of AR with different orders, we can rewrite the equations (1) and (3) in the form as follows:

$$
\beta \xi_{i}+\sum_{v=1}^{m}(-1)^{v-1} \cdot C_{m}^{v} \cdot \rho^{v} x_{i-l}=x_{i}, i=1,2,3, \ldots
$$

Where $m$ is the order of autoregression? Multiplying (4) by $x_{i-k}$ and finding the mathematical expectations of the right and left sides of such an equality, we get, after dividing by $\sigma_{x}^{2}=M\left\{x_{i}^{2}\right\}, i=1,2, \ldots, n$, The following relation for the values of the normalized correlation function $[8,12,15]$ : 
but in an explicit form:

$$
F_{x}(k)=\sum_{v=1}^{m}(-1)^{v-1} \cdot C_{m}^{v} \cdot \rho^{v} F_{x}(k), k>0
$$

$$
F_{x}(k)=m \rho F_{x}(k-1)+(-1)^{1} C_{m}^{2} \rho^{2} F_{x}(k-2)+\ldots+(-1)^{m-1} \rho^{m} F_{x}(k-m), k>0
$$

In [15], their correlation properties are analyzed and relatively simple asymptotic relationships for the correlation intervals $(k)$ are found. The asymptotic formula obtained allows finding the correlation interval of the autoregression sequence with the roots of the characteristic equation of any multiplicity $m$. For relatively small correlation intervals $\left(k_{0}\right)$, to find them, it is need to use directly the expression for correlation function $F_{x}(k)$. The data of [16] contains an analysis of the characteristic polynomial of the second-order autoregressive process with complex roots using Yule-Walker equations. Nevertheless, the YW equations associated with asymptotic displacement formula still bounded in precision. The article [17] considers an estimation parameters of linear AR model in case of presence of additive and uncorrelated measurement errors. This will make it possible to use heterosquadity in the variance of measurement errors. The asymptotic properties of new estimates are established and ignore the measurement error. Also, proposed estimation based on correction of the Yule-Walker evaluation equations. Moreover, the method of pseudo-libism was considered, based on assumptions about normality and calculated using the Kalman filter. The work of [18] present a definition of the parameters of autoregressive models that help to obtain random fields closely in characteristics to isotropic. The author proposes to use the YW systems to find the correlation coefficients from a given correlation function. In [4], several kinds of AR for time series analysis are presented for instance: i) one-dimensional and multidimensional autoregressive models, ii) an AR with exogenous variables, iii) a locally stationary autoregressive model, iv) an autoregressive model of a radial basis function. With the help of these models, various tools are obtained for the analysis of dynamic systems, such as the impulse response function, power spectrum, characteristic roots and energy contribution. In [19], a unified quasi likelihood procedure was proposed for estimating unknown parameters of AR (1) random coefficient under both for stationary and non-stationary processes. In [20], a complex AR model based on the mathematical derivation of least squares for a complex numerical domain was investigated. This model differs from the conventional one, since the real and imaginary numbers are calculated individually. Appendix of [20] shows that the use of a complex number to place the field of meteorological elements. Predicting using a complex autoregressive model is effective in improving the results of the forecast. In [21], one of the possible approaches to the interpretation of experimental data based on the theory of linear dynamical systems is considered. The analyzed data are considered as an output of some linear dynamical system, described by an ordinary differential equation (ODE) of the $1^{\text {st }}$ order. A method is proposed for identifying the ODE parameters from the current data without involving any a priori information.

The proposed approach to modeling allows: to identify the statistical parameters of the noise present in the data; build optimal filters; organize bandpass filtering and signal separation; to study the structure of complex processes and many other tasks, minimum of a priori information. In [22] the monograph describes the geometric method. These solutions are objective in the sense that they have a firm theoretical basis and use the modeling of nonlinear dynamical systems from experimental data. The basis of the method is a qualitative approach to the analysis of nonlinear models and the construction of groups of symmetries of attractors of dynamical systems with controls. In [23], the problem of approximating a continuous model from the discrete data observed in its connection with 
the Laplace transform and the z-transformation is considered. It is obtained that the relationship between ordinary differential and difference equations established by us is analogous to the inverse coordinated z-transformation, when passing from the complex $\mathrm{z}$ plane to the s-plane. A comparative analysis of the proposed and classical methods of transition from a continuous to a discrete model (and vice versa) is performed. The paper [24] offers a new set of transformed polynomial functions that deliver a flexible setting for nonlinear autoregressive modeling of the conditional mean and concurrently ensure strict stationarity, ergodicity, damped memory, and the existence of moments of the supposed stochastic sequence. The great flexibility of the transformed polynomial functions makes them interesting for both parametric and semiparametric autoregressive modeling. This flexibility is proven by showing that the transformed polynomial sieves are super-normed on the space of continuous functions and provide corresponding convergence rates in Holder functional spaces.

On difference equations and autoregressive processes, we find that many seemingly complex mathematical objects, such as eigenvalues, diagonalized matrices, unit roots and nonstationary processes. The eigenmodes estimating and intervals matching with their oscillation periods and damping times can be calculated from estimating parameters of the model. The works $[27-37,56]$ contains data analysis collected at each spatial location and during time intervals and time dependence between different implementations. Also contains proposals, forms and applications based on AR (m).

\section{THRESHOLD AUTOREGRESSIVE MODEL (TAR)}

Tong (1978) and Tong \& Lim (1980) [39] are introduces threshold time series models which have been effective. Via its piecewise-linear nature, the TAR model can simulate non-linear features like limit cycles, resonance and others as well as it is easily quantifiable. So, there are sudden variation in the probability structure when the threshold process is switch modes which may not take place in the real life. TARs usually work well, excluding for the boundaries between different regimes [38, 39]. Particularly, the TAR model produced a wide range of articles covering both theoretical and empirical problems.

Let us a self-excited hysteresis AR model with a mode indicator $R_{t}[39]$ :

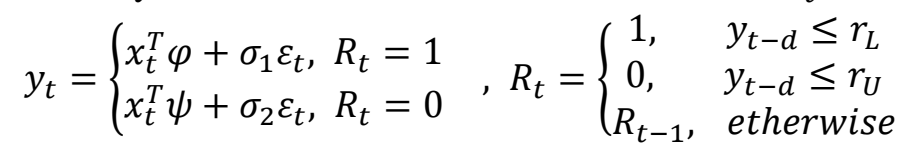

where $\quad x_{t}=\left(1, y_{t-1}, \ldots, y_{t-m}\right)^{T}, \varphi=\left(\gamma_{1}, \varphi_{1}, \ldots, \varphi_{m}\right)^{T}, \psi=\left(\gamma_{2}, \psi_{1}, \ldots, \psi_{m}\right)^{T}, \quad \varepsilon_{t}-\quad$ are independent and distributed random variables identically with zero mean and unity variance, $\sigma_{1}, \sigma_{2}>0-$ are scalars, $d>0-$ delay parameter, and $r_{L} \leq r_{U}$ - are the border parameters of the hysteresis zone. Eq. (7) includes a traditional two-mode TAR as a special case for $r_{L}=r_{U}[38,39]$.

From (7), the mode indicator becomes

$$
\begin{gathered}
R_{t}=I\left(y_{t-d} \leq r_{L}\right)+I\left(r_{L}<y_{t-d}<r_{U}\right) R_{t-1} \\
=I\left(y_{t-d} \leq r_{L}\right)+\sum_{j=0}^{\infty} \prod_{i=0}^{j} I\left(r_{L}<y_{t-d-i} \leq r_{U}\right) I\left(y_{t-d-j-1} \leq r_{L}\right)
\end{gathered}
$$

almost surely. When $r_{L}<r_{U}$, then the mode indicator depends upon the past observation which are infinitely far away and makes the hysteresis model differs from the traditional threshold models [38, 39]. In [40], a method is proposed for defining regimes number in TAR using a smooth transient (ST) autoregression as a tool. Since the ST model is TAR(1) estimation, but asymptotic properties are not supported for the proposed method. The existing tests for the adequacy of AR model with ST regime are applied sequentially to 
determine the mode number. However, the hysteresis AR model is widely known in economics, engineering, mechanics, materials science, and so on. In [38, 39], a typical twomode TAR is extended which leads to produce a new model called a hysteresis autoregressive model. This proposing a hysteresis into its mode switching structure. The proposed model uses a piecewise linear structure of TAR model with more flexible mechanism for switching modes. An adequate condition for geometric ergodicity is given and the estimation of conditional least-squares was discussed. Asymptotic distributions and information criteria for model selection are derived. The derivation in self-excited threshold autoregressive models was discussed in [41]. The main interest is threshold parameter derivation. Asymptotic behavior of the corresponding estimation depends on whether TAR model is continuous or not. In continuous case, the bounding distribution is normal and a standard derivation is possible. In intermittent case, the bounding distribution is abnormal, and it is not known how to evaluate it consistently? In [42], the author is investigating a threshold estimation of TAR model when the basic threshold parameter is a random variable. The author is shown that the Bayesian estimation is matched, but the bounding distribution is expressed in terms of maximum likelihood ratio. In addition, the convergence estimation is also established. The bounding distribution can be calculated by explicit modeling from which the test and output can be performed for the threshold parameter. The results obtained are illustrated by numerical simulation.

\section{EXPONENTIAL AUTOREGRESSIVE (EAR) NONLINEAR TIME SERIES MODEL}

One of the parametric families of the non-linear time series is the exponential autoregression (EAR) model. The EAR model, which introduced to predicts cyclic data, is a kind of useful model that has properties similar to those of non-linear random oscillations. EAR is able to generate data with different types of bound distributions associated with the parametric space in different specific areas. EAR also deals with the amplitude-dependent frequency, transition phenomena and the limit cycle. A reflective feature of this model is that it fixes the non-Gaussian characteristics of time series and also has a marginal distribution belonging to the exponential family $[1,43]$.

The EAR $(m)$ model can be explicitly written as

$$
y_{i+1}=\left\{\varphi_{1}+\rho_{1} e^{-\gamma y_{i}^{2}}\right\} y_{i}+\ldots+\left\{\varphi_{m}+\rho_{m} e^{-\gamma y_{i}^{2}}\right\} y_{i-m+1}+\xi_{i+1}
$$

from $\gamma>0$, a certain scaling constant and $\xi_{i+1}-$ is the process of white noise with an average zero and variance $\sigma_{\xi}^{2}$.Values $\gamma$ are selected in such a way that $e^{-\gamma y_{i}^{2}}$ varies significantly over the range (0.1). In addition, (9) can be considered as a threshold AR model. If $\left|y_{i}\right|-$ a large value, then (9) is analogous to an AR model with parameters approximately equal to $\left(\varphi_{1}, \ldots, \varphi_{m}\right)$. But if $\left|y_{i}\right|-$ small value, the autoregression parameters are switched to $\left(\varphi_{1}+\rho_{1}, \ldots, \varphi_{m}+\rho_{m}\right)[1]$.

\section{DOUBLE AUTOREGRESSIVE MODEL (DAR)}

Let us consider the autoregression model with conditional hetero-dependence [44]:

$$
y_{t}=\sum_{i=1}^{p} \varphi_{i} y_{t-i}+\eta_{t} \sqrt{\omega+\sum_{i=1}^{p} \alpha_{i} y_{t-i}^{2}}
$$

where $\omega, \alpha_{i}>0, t \in N \equiv(-p, \ldots, 0,1,2, \ldots), \eta_{t}-$ is an independent random sequence, $\eta_{t} \approx N(0,1)$, and $y_{s}$ does not depend on $\left\{\eta_{t}: t \geq 1\right\}$ for $s \leq 0$. Consider $F_{t}$ will be $\sigma-$ field generated $\left\{\eta_{t}, \ldots, \eta_{1}, y_{0}, \ldots, y_{p}\right\}, t \in N$. The conditional variance for is $\operatorname{var}\left(y_{t} \mid F_{t}\right)=\omega+\sum_{i=1}^{p} \alpha_{i} y_{t-i}^{2}$. The 
data of [45] contains studies of a non-stationarity $1^{\text {st }}$ order DAR model which is determined by the random recurrence equation: $x_{i}=\varphi_{0} x_{i-1}+\xi_{i} \sqrt{\gamma_{0}+\alpha_{0} x_{i-1}^{2}}$, where $\gamma_{0}>0, \alpha_{0} \geq 0$ and $\xi_{i}-$ a sequence of symmetric random variables. This is shown that the first-order DAR model is explosive on condition $\mathbb{E} \log \left|\varphi_{0}+\xi_{i} \sqrt{\alpha_{0}}\right|>0$. According this condition, the quasi-maximal likelihood of $\varphi_{0}, \alpha_{0}$ is consistent and normal asymptotically, so that the problem of the unit root does not exist in (10) [44].

\section{VECTOR AUTOREGRESSIVE MODELS (VAR)}

Vector AR processes are popular in sciences, especially in economics [46]. VAR model is flexible and simple for multi-dimensional time series data. For example, in econometrics, VAR became standard tools when classical models of simultaneous equations were identified and recommended as alternative [46,47]. The main form of the VAR process is:

$$
y_{t}=D d_{t}+A_{1} y_{t-1}+\ldots+A_{m} y_{t-m}+\xi_{t}
$$

where $y_{t}=\left(y_{1 t}, \ldots, y_{K t}\right)^{T}-$ is the vector $K$ of observed variables of time series, a vector of deterministic terms such as a constant, a linear trend and/or seasonal dummy variables; D is a bound parameter matrix; $\left(A_{1}, \ldots, A_{m}\right)$ - are the parameters of matrices $(K \times K)$ tied to retarded values $y_{i} ; m$ - is the VAR order; $\xi_{t}-$ is a white noise with zero mean and considered error process; $E\left(\xi_{t}\right)=0, E\left(\xi_{t} \xi_{t}^{T}\right)=\sum_{\xi}$ - is an invariant in time and all $\xi_{t}$ are consistently uncorrelated or independent. VAR models are useful tools for forecasting and also can be used to analyze the relationship between the variables involved [46,47]. The work [48] solve the problem of determining the time direction in VAR processes by using statistical method. By analogy with causal of $\mathrm{AR}_{(1)}$ processes with non-Gaussian noise, the time-reversal remnants distribution of the linear vector $\mathrm{AR}_{(1)}$ model is assumed closer to the Gaussian distribution than the actual remnants distribution in the forward direction. Experiments with simulated data show the validity of the hypothesis. According to obtained results, a decision rule was developed to determine the direction of VAR processes. The correct direction in time (forward direction) is the remainders of time series which less than Gaussian. A number of experiments illustrate the excellent results of the proposed rule as compared to other methods based on independence tests. In [49-52], VAR models with controlled resolution are offered, which allows controlling various sizes of sparsity, allowing to correctly visualizing potential causes and dependencies. The coefficients of the model are found as a solution to the problem of mathematical optimization, solvable by standard numerical optimization routines. In [53], the properties of the steady-state of the threshold VAR are considered. Suppose that the regime process follows the Bernoulli distribution and the trigger parameter is exogenous, necessary and sufficient conditions for the existence of a stationary distribution are derived. In [54], the problem of detecting anomalies in heterogeneous multidimensional multi-parameter sets of time series is considered. The focus is on the field of safety, in which data objects are flights, and time series are sensor readings and control switches. The paper proposes a structure that represents each flight using autoregression using polarization with Markov switching. When adjusting the VAR with correlated noise, despite the strong time dependence and covariance, [55] set the error bounds for the non-asymptotic evaluation of the structured parameters of the VAR. The estimation error has the same order as the corresponding Lasso type evaluation block with independent samples and the analysis is performed for any norm. The analysis is based on the results of the generalized chain; sub exponentially martingales, and the spectral representation of the VAR models. 


\section{CONCLUSIONS}

This article presents a brief literature review containing developments related to the AR model. Also, including several extensions of the main regime model and recently developed models \& methods for estimating forecasts. This class of tasks is relatively new and research on the topic contains certain contradictions. For example, among researchers there is no unity in the use of various concepts, terms and formulations to designate solved problems. Moreover, there is no qualitative classification of tasks and methods for solving them, and the proposed classifications are incomplete. For example, for image analysis, mathematical models of random fields are used. However, the used autoregressive models have the property of anisotropy, therefore, to describe the majority of real images that are isotropic; a model with multiple roots of characteristic equations is better suited

Sometimes used models that are implemented on various geometric shapes and this implementation cause additional computational complexity (i.e. the transition to twice stochastic models of random fields' leads to an increase in computational costs). Their use allows obtaining heterogeneous results, since the parameters of the model are constantly changing. The change of parameters, as a rule, is described by a usual autoregressive random field, and then some transformation occurs. As noted earlier, autoregressive models are used to describe random fields on multidimensional space. A special case is represented by autoregression processes of large orders (section II). However, the construction of such models should begin with a one-dimensional space and the characteristics of quality models are stability and accuracy, in which the minimum variance of the control error is ensured. Finally, the variety of different models of random fields currently used have completely different structures and impossible describe them with one model.

\section{REFERENCES}

[1] Bishal Gurung, «An Application of Exponential Autoregressive (EXPAR) Nonlinear Time-series Model» // International Journal of Information and Computation Technology, Volume 3, Issue 4, 2013, pp. 261-266.

[2] By Rong Chen , Lon-Mu Liu, «Functional Coefficient Autoregressive Models: Estimation And Tests Of Hypotheses» // Journal of Time Series Analysis, Volume 22, Issue 2, March 2001, pp. 151-173

[3] Van Dijk, D., T. Teräsvirta, P.H. Franses, «Smooth Transition Autoregressive Models-A Survey Of Recent Developments» // Econometric Reviews, vol.21, 2002,pp1-47.

[4] Ohtsu K., Peng H., Kitagawa G., «Time Series Analysis Through AR Modeling. In: Time Series Modeling for Analysis and Control» // Springer Briefs in Statistics, Springer, Tokyo, 2015,pp. 7-56.

[5] Бокс Дж., Дженкинс Г., «Анализ временных рядов. Прогноз и управление» / Пер. с англ.; под ред. В.Ф.Писаренко. - М.: Мир, 1974. - Вып.1. - 406 с.

[6] Васильев К.К., Драган Я.П., Казаков В.А., Крашенинников В.Р., Кунченко Ю.П., Омельченко В.А., Трифонов А.П., Спектор А.А., «Прикладная теория случайных процессов и полей» / под ред. Васильева К.К. и Омельченко В.А. - Ульяновск: УлГТУ, 1995. - 256 с.

[7] Vasilyev K.K., Popov O.V., «Autoregression models of random fields with Multiple Roots» // Pattern recognition and Image analysis, 1999, v.9, №2, pp.327-328.

[8] Васильев К.К. «Авторегрессии с кратными корнями характеристических уравнений». - М.: Радиотехника, 2014, №11, с.74-76.

[9] Васильев К.К. «Оптимальная обработка сигналов в дискретном времени»: учеб. пособие. - М.: Радиотехника, 2016. - 288 c.

[10] Васильев К.К., Крашенинников В.Р. «Статистический анализ последовательностей изображений». - М.: Радиотехника, 2017. - 248 с.

[11] Васильев К.К., Попов О.В., «Авторегрессионные модели случайных полей с кратными корнями»//Труды 4-й конф. «РОАИ: новые информационные технологии» Новосибирск, 1998 .- С. 258-260. 
[12] Васильев К.К., Андриянов Н.А. «Анализ авторегрессий с кратными корнями характеристических уравнений»// Радиотехника. 2017. № 6. - С. 13-17

[13] Кудряков С.А., «Радиотехнические цепи и сигналы». (Учебное пособие).- С. Пб.: Изд-во «Свое Издательство», 2015.- $340 \mathrm{c}$.

[14] Рыжкина Т.А., Старовойтова 3.П., «Моделирование устойчивых фильтров для стохастических процессов» // Научные труды Дальрыбвтуза.-Дальневосточный государственный технический рыбохозяйственный университет.- Том 34-2015.

[15] Васильев К. К., Служивый М. Н. «Математическое моделирование инфокоммуникационных систем». Учебное пособие для вузов. - М.: Горячая линия - Телеком, 2018. - 236 с.

[16] Saeid M. Assadi, «Evaluation of the bias of yule-walker estimates in autoregressive time series processes» / Master thesis, San José State University, USA,2006, P. 53.

[17] Staudenmayer, John, and John P. Buonaccorsi, «Measurement Error in Linear Autoregressive Models» // Journal of the American Statistical Association, vol. 100, No. 471, 2005, pp. 841-852.

[18] Андриянов Н. А., Дементьев В. Е., «Применение системы уравнений Юла-Уолкера для имитации изотропных случайных полей» // Междунар. науч. конф. - Казань: 2015. - с. 2-6.

[19] Alexander Aue, Lajos Horvath, «Quasi-Likelihood Estimation In Stationary And Nonstationary Autoregressive Models With Random Coefficients»// Statistica Sinica, vol.21, 2011, pp. 973-999

[20] X. Gu, J. Jiang, «A complex autoregressive model and application to monthly temperature forecasts»//Annales Geophysicae, Volume 23, Issue 10, 2005, pp.3229-3235.

[21] Ю.П. Драница, А.Ю. Драница, «Некоторые аспекты интерпретации экспериментальных данных на основе теории линейных динамических систем» // Вестник МГТУ, том 12, №1, 2009 г. стр.125-131.

[22] Никульчев Е. В., «Геометрический подход к моделированию нелинейных систем по экспериментальным данным» / Монография, Федеральное агентство по образованию Государственное образовательное учреждение высшего профессионального образования «Московский государственный университет печати», Москва, 2007, с162.

[23] Драница Ю.П. , Драница А.Ю., Алексеевская О.В., «О связи непрерывной и дискретной моделей для ленейных динамических систем»// Дифференциальные уравнения и процуссы управления, №3,2010, с. 20-57.

[24] Francisco Blasques, «Transformed Polynomials for Nonlinear Autoregressive Models of the Conditional Mean»// Journal of time series analyses, Volume35, Issue3, 2014, pp. 218-238.

[25] Marc-Andreas Muendler, «Linear Difference Equations and Autoregressive Processes» // University of California at Berkeley, February 17, 2000, p.28.

[26] Arnold Neumaier, Tapio Schneider, «Estimation of parameters and eigenmodes of multivariate autoregressive models»// Journal of ACM Transactions on Mathematical Software (TOMS), Volume 27 Issue 1, March 2001 , pp. 27-57.

[27] Ulrich Herkenrath, Marius Iosifescu, Andreas Rudolph, «Linear Autoregressive Models» // Math. Reports, Vol. 12(62), Issue (3), 2010, pp. 245-259

[28] Karima Nouali, «Robustness Of Estimation Of First-Order Autoregressive Model Under Contaminated Uniform White Noise» // Discussiones Mathematicae Probability and Statistics, Vol.29.-Issue 1, 2009,pp. 53-68.

[29] Jia Zhou, «Smooth Transition Autoregressive Models A Study Of The Industrial Production Index Of Sweden» / A Thesis of master degree, Uppsala University, 2010.

[30] S. Ganapathy, S. Thomas, P. Motlicek, and H. Hermansky, «Applications of signal analysis using autoregressive models for amplitude modulation»//in Applications of Signal Process. to Audio and Acoust. (WASPAA), IEEE Workshop on, 2009, pp. 341-344.

[31] Wang D., and Ghosh S.K., «Bayesian analysis of random coefficient autoregressive models»// Model Assisted Statistics and Applications, vol.3, 2002, pp. 281-295.

[32] Sophie Lambert-Lacroix, «On periodic autoregressive processes estimation» // IEEE Trans. Signal Processing 48 (2000): pp.1800-1803.

[33] Andreas Heinen, «Modelling Time Series Count Data: An Autoregressive Conditional Poisson Model»// CORE Discussion Paper No. 2003-63 (2003)

[34] Nielsen, Bent and Nielsen, «Heino Bohn, Properties of Estimated Characteristic Roots»// Univ. of Copenhagen Dept. of Economics Discussion, (May 2008), Paper No. 08-13.

[35] Robert Serfling, Fitting autoregressive models via Yule-Walker equations allowing heavy tail innovations, Mimeo (2010), Available at http://www.utdallas.edu/ serfling/papers/Serfling2010_AR_MR.pdf

[36] Mariella, L., \& Tarantino, M. Spatial Temporal Conditional Auto-Regressive Model: A New Autoregressive Matrix. Austrian Journal of Statistics, (2016), 39(3), 223-244.

[37] Pierre Ailliot, Valrie Monbet, Markov-switching autoregressive models for wind time series, Environmental Modelling \& Software, Elsevier Science Publishers B. V. Amsterdam, The Netherlands, The Netherlands, Volume 30, April, 2012, Pages 92-101. 
[38] Guodong Li, Bo Guan, Wai Keung Li , Philip L.H. Yu, Hysteretic Autoregressive Time Series Models //Biometrika (2012), Vol. 99, Issue 1, pp. 1-8

[39] Guodong Li, Bo Guan, Wai Keung Li, Philip L.H. Yu, Hysteretic Autoregressive Time Series Models //Biometrika, Vol. 102, Issue 3, 1 september 2015, pp. 717-723.

[40] Strikholm B., Teräsvirta T. "Determining the number of regimes in a threshold autoregressive model using smooth transition autoregression", 13th EC2 Conference, Model Selection and Evaluation, Bologna, Italy, December 13-14, 2002.

[41] Gonzalo, J. and Wolf, M. Subsampling inference in threshold autoregressive models// Journal of Econometrics 127, (2005), pp. 201-224.

[42] Ngai Hang Chan and Yury A. Kutoyants, On Parameter Estimation of Threshold Autoregressive Models //Statistical Inference for Stochastic Processes, April 2012, Volume 15, Issue 1, pp 81-104.

[43] Baragona, Roberto \& Battaglia, Francesco \& Cucina, Domenico. A note on estimating autoregressive exponential models// Quaderni di Statistica. (2002). Vol 4. P.p.71-88.

[44] Shiqing Ling, A Double AR(p) Model: Structure And Estimation// Statistica Sinica, vol17(2007), pp.161-175

[45] M. Chen, D. Li, S. Ling, Non-stationarity and quasi-maximum likelihood estimation on a double autoregressive model// Journal of Time Series Analysis, vol. 35, (2014). pp.189-202.

[46] Lütkepohl H., Vector autoregressive models // Springer, Berlin Heidelberg, 2011, pp. 1645- 1647.

[47] Lütkepohl H., Vector autoregressive models // European University Institute, ITALY, November 4, 2015, p. 4. https://pdfs.semanticscholar.org/55dd/3b3c84474d897df598551c033184d9adab61.pdf

[48] Morales-Mombiela, Pablo, Daniel Hernández-Lobato, Alberto Suárez, "Statistical Tests for the Detection of the Arrow of Time in Vector Autoregressive Models"// Proceedings of the Twenty-Third International Joint Conference on Artificial Intelligence (IJCAI), 2013, pp. 1544-1550.

[49] Emilio Carrizosa, Alba V. Olivares-Nadal and Pepa Ramirez-Cobo, A Sparsity-Controlled Vector Autoregressive Model, // Biostatistics, Volume 18, Issue 2, 1 April 2017, pp. 244-259.

[50] Moneta, A. ,Chalb, N., Entner, D., \& Hoyer, P., Causal Search in Structural Vector Autoregressive Models. JMLR : Workshops and Conference Proceedings. Vol.12, 2011, pp. 95- 118.

[51] Aapo Hyvärinen, Kun Zhang, Shohei Shimizu, Patrik O. Hoyer. Estimation of a Structural Vector Autoregression model using non-Gaussianity, //Journal of Machine Learning Research, vol.11:pp. 1709-1731, 2010.

[52] Paolo Gorgi, Siem Jan Koopman, Julia Schaumburg, Time-Varying Vector Autoregressive Models with Structural Dynamic Factors, Tinbergen Institute, The Netherlands and Aarhus University, Denmark, p.17, September 27, 2017.

[53] Grynkiv, Galyna and Lars Stentoft. "Stationary Threshold Vector Autoregressive Models." //University of Western Ontario, Social Science Centre, London , (2017). P. 40.

[54] I. Melnyk, B. Matthews, A. Banerjee, and N. Oza., "Semi-Markov switching vector autoregressive modelbased anomaly detection in aviation systems."// Knowledge Discovery and Data Mining, 2016, p.10.

[55] Igor Melnyk, Arindam Banerjee, Estimating Structured Vector Autoregressive Models,// Proceedings of the 33rd International Conference on Machine Learning, New York, NY, USA, 2016. JMLR: W\&CP volume 48.

[56] К.К. Васильев, Н.А. Андриянов, Х.А. Абдулкадим, «Эффективность фильтрации случайных полей с кратными корнями характеристических уравнений» // Радиотехника. 2018. № 6. - С.20-23. 